\title{
Adolescente em conflito com a lei e sua noção de regras no jogo de futsal
}

CDD. 20.ed. 796.05

796.331

\author{
Maria do Carmo Monteiro KOBAYASHI* \\ Valéria Cristina ZANE*
}

*Faculdade de Ciências, Universidade Estadual Paulista - Bauru.

\section{Resumo}

Adolescentes com trajetória de vida alicerçada na falta de valores éticos e morais estão mais vulneráveis à prática de atos infracionais. Caso isso ocorra, o Estatuto da Criança e do Adolescente prevê sua inserção em medidas socioeducativas. Nossa pesquisa tem por objetivo identificar a fase do desenvolvimento moral de adolescentes em conflito com a lei. Para tanto, estudamos 30 adolescentes, entre 15 a 18 anos, do gênero masculino, inseridos em Centro de atendimento socioeducativo. Os dados foram coletados por meio de observação do jogo de futsal, que não contou com a figura do juiz e entrevista estruturada, seguindo-se as linhas gerais do Método Clínico de PIAGET (1994). A categorização dos dados coletados confirmou nossa hipótese - de que esses adolescentes, ainda, se encontram com características de uma moral heteronômica, verificadas pelas diferenças entre a consciência e a prática de regras na situação de jogo. Apesar de conhecerem as regras, durante a partida, somente as respeitam para obterem benefícios, como: não cobrar a falta, enganar o adversário ou, simplesmente, ganhar a partida. Presumimos que somente as respeitariam, caso houvesse a figura de autoridade (juiz), porque esta iria Ihes impor punições e privações. Acreditamos, portanto, que os resultados deste estudo possam tornar-se parâmetros para educadores criarem situações propícias, tanto preventivas como interventivas, para o desenvolvimento sociomoral, minimizando, assim, sofrimentos e oportunizando a formação de cidadãos com maior senso ético e moral, capazes de optarem pelo caminho da solidariedade, da cooperação e da justiça.

UnItERMOS: Jogo de regras; Adolescente em conflito com a Lei; Moralidade; Futsal.

\section{Introdução}

Jovens e adolescentes com trajetória de vida alicerçada na falta de valores éticos e morais apresentam dificuldades para estabelecer o que é certo e o que podem ou não realizar moralmente. Isso os tornam mais vulneráveis à prática de atos infracionais, e caso isso ocorra, sua condição torna-se adolescente em conflito com a lei.

Ressaltamos que atos infracionais, quando cometidos por crianças e adolescentes, esses são amparados pela Lei $\mathrm{n}^{\circ} 8.069$, de 13 de julho de 1990, mais conhecido como Estatuto da Criança e do Adolescente (ECA) (BRASIL, 2006). Essa lei protege e garante os direitos das crianças e adolescentes, tratando-os como pessoas em desenvolvimento. Oportuniza tratamento especial para reeducação e inclusão social dessa população.

Por outro lado, sabemos da importância do jogo de regras e da ação de jogar para o desenvolvimento cognitivo, afetivo, moral e social dos indivíduos.
Para tanto, é necessário a organização, coordenação e operação de uma série de relações, baseadas na natureza lógica.

A ação de jogar propicia o desenvolvimento da aprendizagem e de processos psicológicos, como: atenção, concentração, memória e percepção, além de, socialização e interação entre os indivíduos. Os educadores, através da ação de jogar, poderão diagnosticar dificuldades apresentadas pelas crianças e adolescentes e, assim, oportunizar todo um programa voltado para atender às necessidades e minimizar as dificuldades (KUWAHARA, 2004).

$\mathrm{O}$ jogo de regras também pode ajudar crianças e adolescentes no processo de socialização e inclusão social, porque o papel pedagógico do jogo é educar sentimentos e do ato de jogar é oferecer tarefas determinadas com objetivo de cumpri-la (FONTANA, 1997). 
Este trabalho propôs-se a identificar a noção das regras, de adolescentes em conflito com a lei, entre 15 e 18 anos, durante a partida do jogo de futsal. Para tanto, utilizamos a observação da partida do jogo de futsal e a entrevista estruturada, conforme, linhas gerais do Método Clínico de Piaget (1994) para a identificação da questão proposta.

Acreditamos que o reconhecimento da noção de regras, dos adolescentes em conflito com a lei, no jogo de futsal, possibilitará práticas educativas mais eficientes na promoção de questionamentos para ajudá-los no desenvolvimento da aquisição de valores direcionados para o respeito mútuo, a cooperação, a solidariedade e a responsabilidade. Assim, a ressocialização e a diminuição da reincidência desses adolescentes, em medida socioeducativa de internação poderão ser favorecidas.

\section{A importância do jogo de regras}

Quando nos referimos ao ato lúdico, podemos incluir brinquedos, divertimentos e o que é relativo a jogos. A atividade lúdica é uma possibilidade para crianças, jovens e adultos, desenvolverem a capacidade cognitiva, afetiva, motora e moral. Possibilita a aprendizagem de conceitos, mais elaborados, como imagem corporal, lateralidade e orientação temporal. Também estimula e facilita o processo de socialização e interação com os demais.

No ato de brincar e nas brincadeiras, não há necessidade do uso de regras rígidas para desenvolvêlas. A partir da vivência, da criança, durante a brincadeira, ela constrói seus personagens. No jogo, ao contrário, utilizamos regras para definir ganhadores e perdedores, e os indivíduos interagem com o objetivo de jogar para competir e ganhar.

Piaget (1975) estudou os jogos e sua importância para a teoria construtivista. Ele realizou classificações dos jogos, baseadas na evolução das estruturas mentais, ligadas aos estágios de desenvolvimento cognitivo infantil. Concluiu que, ao longo do desenvolvimento cognitivo da criança, ocorrem três formas de jogos: o jogo de exercício, o jogo simbólico e o jogo de regras.

Para Piaget (1975), os jogos de competição e cooperação são a base do trabalho lúdico, com crianças e adolescentes, pois a regra garante a posição de cada um, no grupo, e favorece a discussão e interlocução dos indivíduos, na obtenção dos resultados.

$\mathrm{O}$ ato lúdico permite desenvolver a aprendizagem e a ação de jogar a compreender regras e normas. Toda uma estrutura lógica, baseada na compreensão, coordenação e organização é mobilizada na hora do jogo (KuWAHARA, 2004).

Regras são importantes porque são partes integrantes da sociedade. $\mathrm{O}$ jogo com regras possibilita à criança, desenvolver suas estruturas mentais e socializar-se. Na infância, a moralidade é passiva, porque as crianças obedecem às regras sem discuti-las.

Há implícito, no jogo, um dever e uma tarefa moral. Sua utilização, por crianças, adolescentes e adultos, desperta a curiosidade, a habilidade social e desenvolve a capacidade cognitiva. A relação interpessoal estabelecida entre os pares, na hora do jogo, promove o avanço nas relaçōes sociais, de modo geral (FONTANA, 1997).

Assim, o jogo nos dá um dever e uma tarefa moral e é através da sua utilização que crianças, jovens e adultos relacionam-se com os ambientes físicos e sociais em que vivem, despertando suas curiosidades, habilidades e conhecimentos, além de fornecer o avanço do aprendiz nas relações sociais de maneira geral.

O jogo, principalmente, de regras, pode viabilizar seres mais éticos, conscientes e comprometidos com a cultura e os valores, e assim, favorecer a construção de uma sociedade mais justa e menos excludente.

Com a utilização do conceito teórico, preconizado por Piaget (1994) a respeito do desenvolvimento moral, o educador poderá concretizar projetos que provoquem transformações positivas na sociedade.

\section{Desenvolvimento moral de Jean Piaget}

A moralidade vem sendo um assunto amplamente difundido no ambiente educacional. Seu estudo se faz necessário para ressaltarmos a importância da formação de cidadãos críticos e participativos dentro do contexto social. O senso de justiça desenvolvido, entre as pessoas, deve ser baseado na igualdade e cooperação entre os homens.

Sabemos que o estudo da Ética e da Moral possibilita ao educador o planejamento de atividades para estimular o adolescente a rever, através de dilemas, seus valores éticos e morais. Isso refletirá em novas condutas e atitudes direcionadas a melhorar sua interação com o mundo.

Jean Piaget (1994), precursor da teoria do desenvolvimento moral, inicia pesquisas, com enfoque psicogenético, sobre as relações de respeito e lei moral. Para tanto, entrevistou alunos de escolas, da cidade de Genebra e Neuchâtel, questionando-os sobre problemas morais.

Os resultados dos estudos estão expostos na obra intitulada $O$ juizo moral na criança (PiAget, 1994). 
Nessa obra, ele apresenta várias pesquisas, no domínio da moralidade, utilizando jogos de regras, para verificar o desenvolvimento da moral na criança. Piaget utiliza jogos de regras, porque os considera "[...] admiráveis instituições sociais” (PIAGET, 1994, p.23).

As regras do jogo e as regras morais, para PIAGET (1994), são transmitidas de geração para geração e se mantêm, unicamente, graças ao respeito das pessoas por elas.

No entanto, esse epistemólogo acredita na existência de uma diferença essencial, ou seja, enquanto as normas morais são impostas pelos adultos; as regras do jogo, pelo contrário, são elaboradas, apenas, pelas crianças. $O$ fato de que essas regras não apresentavam um conteúdo moral, propriamente dito, não era relevante para ele, mas, sim, de emanarem de indivíduos respeitados. Uma das grandes perguntas elaboradas por Piaget, diz respeito às origens das regras: "[...] inventadas pelas crianças ou impostas pelos pais e adultos em geral?" (PIAGET, 1994, p.32).

A correlação que PIAGET (1994) faz entre a prática e a consciência da regra é apenas estatística, isto é, quantitativa, mas, como ele afirma, em linhas gerais, parece haver uma relação. Segundo Piaget (1994), a regra coletiva é, inicialmente, algo exterior ao indivíduo e sagrada, depois vai se interiorizando e aparece como livre resultado do consentimento mútuo e da consciência autônoma.

Com seus estudos, Piaget (1994) obteve, do ponto de vista da prática das regras, quatro estágios sucessivos e, do ponto de vista da consciência das regras, três.

O primeiro estágio da prática das regras (característico de crianças de até três anos) é, puramente, motor e individual. Nesse estágio, a criança manipula os objetos, em função dos hábitos motores e dos próprios desejos. Para PiagET, a criança estabelece "[...] esquemas mais ou menos ritualizados, mas, permanecendo o jogo individual, ainda não se pode falar senão de regras motoras e não de regras propriamente coletivas" (1994, p. 33). A principal característica do estágio, segundo Piaget (1994) é a relação individual estabelecida, pela criança, com esquemas ritualizados e sua aplicação funcional, através dos esquemas de ação.

O segundo estágio da prática das regras (compreende a idade de dois a cinco anos). É chamado de egocêntrico e tem início quando a criança recebe, o exemplo de regras codificadas. A criança pode jogar sozinha ou com outros parceiros do seu modo ou de acordo com o que aprendeu, em encontros anteriores, com seus parceiros.
Piaget (1994) explica que, nesse estágio, as crianças jogam para si e todas podem ganhar ao mesmo tempo. Por imitarem e utilizarem os exemplos recebidos, esse estágio é chamado de egocêntrico. Conforme Christino (2006), a imitação dos maiores está sujeita ao egocentrismo. Ela se torna mais um exemplo interessante que uma realidade obrigatória. Não há codificação das regras e nem uniformização das diferentes maneiras de jogar. $\mathrm{O}$ que importa é sair jogando e pronto.

O terceiro estágio da prática das regras (a partir dos sete ou oito anos) é denominado por Piaget (1994) de estágio de cooperação nascente. Aqui, surge a tendência e interesse para descobrir regras fixas, comuns a todos e de controle mútuo. No entanto, quando interrogados sobre regras, as informações são diferentes e contraditórias, mesmo jogando um único jogo. Nesse estágio, a criança não domina detalhes das regras, por estar no período de raciocínio operatório concreto, e, quando questionadas, a interpretação fornecida é individual. O importante, nesse estágio, é a premissa de ganhar e vencer parceiros. As principais características do terceiro estágio são: a regra normatiza a ação entre os competidores; o prazer motor é acrescentado pelo gosto da vitória sobre o oponente; há respeito rigoroso pelas regras e vigia aos oponentes e, caso haja o descumprimento das regras, considerarão delito grave.

O quarto estágio da prática das regras (surge aos 11 ou 12 anos) é denominado de codificação das regras. Nesse estágio, as partidas, os pormenores dos procedimentos e o código de regras são conhecidos por todos. Quando questionados sobre regras e possíveis variações, fornecem informações de notável concordância.

As principais características desse estágio são: a utilização de estratégias para vencer e tirar proveito da própria regra e a elaboração e discussão de novas regras e estratégias de jogo.

Quanto à consciência das regras, para PIAGET (1994, p.50), "[...] não se pode isolar a consciência das regras do jogo do conjunto da vida moral da criança”, porque, desde muito cedo, as crianças assimilam, inconscientemente, as regras as quais são submetidas.

Para explicar o desenvolvimento da consciência das regras, nas crianças, PIAGET (1994) a dividiu em três estágios, e enfatizou a articulação entre desenvolvimento moral e processo cognitivo.

Piaget (1994) refere-se ao primeiro estágio da consciência das regras como puramente individual e egocêntrico. Salienta que, no decorrer do jogo, "[...] a criança joga bolinhas como bem entende, procurando satisfazer seus interesses motores ou sua fantasia simbólica" (PIAGET, 1994, p.50). 
Nesse estágio, as regras são exemplos interessantes, procedentes da figura de autoridade, e a criança interessa-se mais pelos rituais inventados que as regras, propriamente, sugeridas pelo grupo.

As características principais desse estágio são: a não-obrigatoriedade das regras, porque a criança não valoriza sua necessidade. Assim, não as praticam, não possui respeito intelectual por elas, aceita apenas as mudanças e sua origem está atribuída à criação divina, mitológica ou paterna.

O segundo estágio da consciência da regra ocorre entre o apogeu do egocentrismo e primeira metade do estágio da cooperação. Segundo Piaget (1994), para a criança, a regra é considerada sagrada, intangível, de origem adulta e de essência eterna. Toda modificação proposta será considerada, pela criança, como transgressão (Piaget, 1994).

Nesse estágio, as principais características são: obrigatoriedade da regra é sagrada, caso haja qualquer modificação ou adaptação à regra tradicional do jogo, isso será considerado ilegítimo, apesar de possuir competências para criar novas regras, manifesta-se contrária às regras "inventadas" e a origem da regra é divina e paterna.

O terceiro estágio da consciência da regra compreende o quarto estágio da prática das regras. Segundo Piaget (1994), nesse estágio, a regra é considerada uma lei, mantida por consentimento mútuo e por lealdade ao grupo, ela deve ser respeitada e mudanças poderão ocorrer, somente, por consenso geral. A consciência do caráter arbitrário e necessário das regras tem origem na cooperação e aceitação mútua entre os competidores.

Conforme citado por Diaz-Aguado e Medrano (1999, p.20), a moralidade "[...] depende do tipo de relação social que o indivíduo mantém com os demais e existem, portanto, tantos tipos de moral como de relaçõos sociais". De acordo com tal hipótese, Piaget (1994) distingue duas formas diferentes de moral: a heterônoma, baseada na obediência, na coerção e punição e a autônoma, fundamentada na igualdade, no respeito mútuo e na cooperação. Postula que a condição necessária para a autonomia é a relação mantida com os companheiros.

As características principais da fase da heteronomia, conforme Diaz-Aguado e Medrano (1999) e confirmadas pela teoria de PIAGET (1994) são: a regra é imposta, a partir do exterior, como um sistema de regras obrigatórias; apresenta caráter coercitivo e obrigatório, fundamentada no princípio de autoridade, no respeito unilateral e nas relaçõos de pressão; sua prática é limitada e egocêntrica, a responsabilidade do ato é julgada pelas consequências materiais, denominada de realismo moral; a noção de justiça está baseada na obediência à autoridade e na ação para evitar castigos, proibições e castigos têm a função de expiação e devem ser necessárias, dolorosas e, arbitrariamente, castigadas, a justiça deixa de ser retributiva para se tornar distributiva, apoiada na igualdade.

$\mathrm{Na}$ fase da autonomia, conforme Piaget (1994), e relatado por Diaz-Aguado e Medrano (1999), suas características são: a regra surge do próprio indivíduo, como um conjunto de princípios de justiça, seu caráter, espontâneo, é fonte do bem, está apoiada no princípio de igualdade, respeito mútuo e nas relações de cooperação. A regra não é fixa e nem estática, mas uma forma de equilibrar relações, sua prática é resultante de decisões livres e racionais; a responsabilidade é julgada em função da intenção; a noção de justiça fundamenta-se na imparcialidade; o princípio de justiça autônomo é o equilíbrio das relaçôes sociais e castigos, antes necessários e recíprocos, convertem-se em algo motivado.

Além dessas fases do desenvolvimento moral, PIAGET (1994) declarou haver uma terceira, chamada de anomia. É caracterizada pela ausência de regras e corresponde à etapa inicial do desenvolvimento do juízo moral infantil. Nessa fase, a criança julga a gravidade da falta em função do resultado ou do caráter material do ato, e não em função da intenção do agente.

Piaget (1994) define essas fases como um processo repetitivo, originário de cada novo conjunto de regras ou plano de consciência ou reflexão. $\mathrm{O}$ desenvolvimento do juízo moral, na criança, passa por uma moral heterônoma, baseada em relações unilaterais, mas não limitante a ela. Para a construção da moral autônoma, a relação de reciprocidade deverá fundamentar-se no respeito mútuo.

A moral da autonomia (último momento do processo de desenvolvimento do juízo moral) deve ser o objetivo de toda educação moral. Para tanto, devemos entender que esse processo inicia-se através da anomia (fase em que há ausência de regras), passa para a heteronomia (fase em que as regras são de origem externa) rumo à autonomia do indivíduo.

O objetivo deste estudo foi identificar a noção de regras de adolescentes, em conflito com a lei, entre 15 e 18 anos, no jogo de futsal. 


\section{Métodos}

\section{Sujeitos}

Foram investigados 30 adolescentes em conflito com a lei, sentenciados a cumprir medida socioeducativa de internação em Centro de atendimento socioeducativo.

A pesquisa teve aprovação do Centro de atendimento socioeducativo, executor da medida socioeducativa de internação, do Juize Promotor de Direito da Vara da Infância e da Juventude da comarca da cidade onde a pesquisa foi realizada e do Comitê de Ética em Pesquisa com Seres Humanos, da Universidade do Sagrado Coraçăo/Bauru, sob o protocolo $n^{\circ}$ 06/07. Os adolescentes foram convidados a participar do estudo, havendo consentimento de todos. Todos os adolescentes e seus responsáveis assinaram o Termo de Consentimento Livre e Esclarecido.

Para a coleta dos dados, selecionamos 30 adolescentes, através do método probabilístico de amostra aleatória simples (BUNCHAFT, Kellner \& HorA, 1998, p.31).

\section{Procedimentos}

As informações foram obtidas de duas maneiras em dois momentos distintos. Primeiro, aplicou-se a entrevista estruturada, conforme o Método Clínico. Esse método foi desenvolvido no decorrer da obra de Piaget, tendo um momento único, em 1926, na introdução da obra A representação do mundo na criança (PIAGET, s/d), onde o autor expressa como surgiu, os ganhos e os cuidados a serem tomados para a utilização desse procedimento metodológico.

Posteriormente, o método foi se transformando conforme os estudos eram realizados. Em 1927, de acordo com Delval (2002, p.58) “[...] o método passa por uma depuração e aperfeiçoamento extraordinário". No entanto, foi a obra $O$ juizo moral na criança, escrita em 1932, que instigou Piaget a apoiar-se na ação do sujeito e fugir da entrevista puramente verbal, "[...] pois a atividade própria do sujeito é um dos principais interesses de todos os seus estudos." (Delval, 2002, p.58)

O instrumento de coleta de dados (KoBAYASHI \& ZANE, 2007) foi constituído de 15 perguntas formuladas, para o estudo. Seis perguntas referentes às regras do futsal e nove sobre situaçōes de jogo, envolvendo dilemas morais.

A entrevista estruturada foi fundamentada nos procedimentos metodológicos do método clínico (Delval, 2002; Piaget, 1994). Esse instrumento permitiu identificar a operação da regra diante de situaçôes que envolvem dilemas morais e observar a constância ou não do valor da regra no momento da análise das situaçóes expostas, que poderá ser utilizado por outros pesquisadores com outros sujeitos.

Segundo Piaget (1994) e Delval (2002), o Método Clínico ajuda o indivíduo a expressar, com próprios termos e sem categorias estabelecidas, questões difíceis de observar de outra forma. A entrevista, por sua vez, representa uma das principais técnicas de trabalho utilizadas em pesquisas por sua grande vantagem em "[...] permitir a captação imediata e coerente da informação desejada, praticamente com qualquer tipo de informante e sobre os mais variados tópicos" e, ainda, "[...] permitir correções, esclarecimentos e adaptações, tornando-se, assim, eficaz na obtenção das informações desejadas" (LUDKE \& ANDRE, 1986, p.34).

No segundo momento, observamos a prática do jogo de futsal entre os adolescentes, bem como as ações e regras aplicadas por eles durante o jogo. Esse procedimento permitiu conhecer o modo de jogo e quais as regras aplicadas por eles, uma vez que regras e ações nos jogos, infantis e juvenis, variam de grupo para grupo, como salienta os estudos de FerRAZ (1997).

Para a verificação da prática e consciência da noção das regras, aplicadas pelos adolescentes, os educadores físicos, apenas, cronometraram as partidas. Solicitamos para não apitarem e nem influenciarem, com palpites ou orientações, os adolescentes. Assim, eles ficariam à vontade para jogarem, e verificaríamos as ações, as regras utilizadas e a dinâmica do jogo.

Observamos as partidas de futsal, dos adolescentes, por uma semana, na arquibancada da quadra poliesportiva. Esse procedimento possibilitou examinar a prática do jogo dos adolescentes deste estudo, bem como subsidiar, com mais fidedignidade, a discussão dos dados.

Para a investigação das respostas coletadas, nas duas fases (entrevista/observação), utilizamos a análise, de dois grupos, dos fenômenos ligados às regras do jogo: a prática das regras, referente à aplicação, e a consciência das regras que situa a fase do desenvolvimento moral desses adolescentes, segundo a fundamentação teórica de PIaget (1994).

Após a coleta de dados, os tabulamos e os agrupamos descritiva, quantitativa e qualitativamente. Com a mensuração, realizamos a discussão com o referencial teórico, previamente, pesquisado. Para a categorização dos dados, utilizamos os conceitos de anomia, heteronomia e autonomia da Psicologia Genética (Piaget, 1994), conforme parâmetros citados e suas adequações às regras do futsal. 


\section{Resultados}

Em linhas gerais, os resultados permitiram verificar a noção das regras, durante a prática do jogo de futsal, com o grupo de adolescentes em conflito com a lei e inseridos na medida socioeducativa de internação. A análise e a categorização dos dados apontam características da fase da heteronomia, proposta por Piaget (1994), nesses adolescentes.

Notamos coerência entre faixa etária e nível de desenvolvimento moral, correspondente ao quarto estágio da prática das regras, caracterizado pela codificação das regras, e ao terceiro estágio da consciência das regras, ambos, pertencentes à fase da heteronomia.

Quanto à consciência da regra, destacamos diante das análises realizadas, que esses adolescentes apresentam características do terceiro estágio da consciência das regras. Nesse estágio, a regra é considerada como lei, imposta por consentimento mútuo, cujo respeito é obrigatório. Para transformála, deve haver um consenso geral no grupo. Observamos a existência da consciência do caráter arbitrário e necessário das regras, resultante da cooperação e aceitação mútua, entre os competidores.

Os adolescentes consideram a hipótese de o jogador ter intenção ou não de provocar a falta. Para Piaget (1994), quando os adolescentes trabalham com hipóteses e julgam o efeito ou resultado produzido pelo ato é porque houve uma mudança para comportamentos manifestos na responsabilidade subjetiva, que considera a intencionalidade do ato e da obrigatoriedade da regra, como aponta o seguinte relato: P (16 anos) "Falta é quando o jogador tem maldade (intenção) de machucar outro jogador".

Confirmamos o caráter coercitivo, de dever e de obrigatoriedade da regra, caracterizado por uma moral de pura obediência. A responsabilidade é julgada em função das consequências materiais da ação.

Deveres são sentidos como obrigatórios, porque provém de sujeitos respeitados, como exemplificados a seguir: W (15 anos) "Quem decide se é falta leve, média ou grave é o juiz"; U (16 anos) "Na falta quem vai decidir se teve ou não intenção é o juiz". Portanto, na fase heteronômica, Piaget (1994) argumenta que a responsabilidade é julgada em função, das consequências materiais, da ação, ou seja, houve ou não intenção de prejudicar pessoas.

Outra característica dessa fase é a prática defeituosa da regra, por ser exterior ao indivíduo. $\mathrm{O}$ adolescente a deforma, ou seja, lhe dá outra forma, conforme a necessidade e a circunstância, e a respeita se houver respeito mútuo pelos colegas.
Não transgridem para não serem punidos, com expulsōes, e nem serem agredidos pelo adversário, o que observamos nas respostas da seguinte pergunta: "Você seria capaz de cometer faltas para ganhar o jogo?". Somente 33,3\%, dos adolescentes cometeriam a falta, sem intenção de machucar o adversário, por medo de expulsão, mas com o objetivo de ganhar o jogo. Metade dos adolescentes $(50 \%)$ optou por não marcar a falta por respeito ao adversário e porque poderiam ser punidos. Apenas $16,7 \%$ da amostra cometeriam ou não faltas, contra o adversário. No entanto, esta decisão dependeria da situação do jogo dentro do campeonato.

$\mathrm{Na}$ fase da heteronomia (Piaget, 1994), o respeito às regras está fundamentado no princípio de autoridade, no respeito unilateral e nas relações de pressão exercida pelo outro. O indivíduo, somente, respeita a regra e a obedece porque há punições, proibições e coerção provenientes de uma autoridade. Respeita-a por medo das consequências de sua transgressão. Nota-se isso nos seguintes relatos: N (17 anos) "Não cometeria a falta porque posso ser expulso e perder o jogo"; M (16 anos) "Não faria porque é um jogo e no jogo você se coloca no lugar do outro jogador (...) não vou gostar, o que não quero comigo não faço pro outro."

Os resultados da questão seguinte, também, confirmam tais características: "Seu adversário está pronto para fazer um gol, você cometeria falta para impedi-lo?”. Cerca de 50\% cometeriam falta por medo da derrota ou porque o adversário poderia fazer o mesmo com seu time, conforme o seguinte relato: A (16 anos) "Faria porque todo jogo é assime ele (adversário) faria o mesmo comigo". Outros 50\% não cometeriam a falta por medo da expulsão, para não machucarem o adversário e por obrigação de aceitar o resultado, como relata o adolescente X (16 anos) "Não faria porque poderia ser expulso, tomar cartão amarelo ou o juiz dar um pênalti."

$\mathrm{Na}$ questão "Você está pronto para marcar o gol, mas o adversário o empurra, com o auxílio das mãos, e o derruba no chão, impedindo o gol, e o juiz nem percebe. Qual sua reação?”. A maioria dos adolescentes $(70 \%)$ conversaria com o juiz para reverter a situação e a minoria (10\%) não conversaria, porque, para eles, o juiz é autoridade máxima, dentro do campo, e sua decisão deve ser respeitada.

Questionados sobre a situação inversa, o resultado é unânime, entre os adolescentes, ou seja, não conversariam com o juiz e deixariam seu time ser 
favorecido pela situação. As características de burlar a lei, não aceitar o que lhe é imposto, pela autoridade, quando não há recompensas a seu favor, podem ser consideradas características presentes na conduta desses jovens, demonstrada nos atos infracionais.

No seguinte questionamento: "Você prefere ganhar a partida, mesmo cometendo falta, violenta, contra o adversário ou prefere perder a partida, mas jogar corretamente". A maior parte dos adolescentes $(96,7 \%)$ optou por perder a partida, porém, jogar corretamente, como relatado por L (18 anos) "Prefiro perder porque posso ser punido pelo juiz" e por R (17 anos) "Prefiro perder (...) podem reconhecer minha maldade e tenho medo de ser cobrado ou que o outro time faça o mesmo comigo". Apenas 3,3\% optaram por cometer falta para ganhar a partida, como narrado por J (17 anos) "Prefiro ganhar e cometer a falta, sem pensar nas consequências".

Os resultados se confirmam na questão seguinte: "Você faria falta violenta no adversário, para marcar um gol, ou você não marcaria o gol, porque cometeria falta grave?". A maioria dos adolescentes $(86,7 \%)$ optou por não cometer falta grave, por medo de puniçōes e represálias do time adversário, como relatado por V (16 anos) "Não marco a falta porque posso ser expulso"; Q (16 anos) "Cometo falta grave só se o outro time fizer" e U (16 anos) "Não faria a falta porque não é certo machucar alguém para garantir a vitória. A vitória deve ser do time que jogar melhor. Também posso prejudicar o meu time e ser expulso e o time fica com menos jogador".

Nota-se que a noção de justiça desses adolescentes, com características da fase da heteronomia (PiageT, 1994) fundamenta-se, primeiramente, na obediência à autoridade e no ato de evitar o castigo. As punições e castigos são necessários e dolorosos e funcionam como expiação, para que as regras sejam respeitadas.

Na questão "Você prefere participar como reserva de um time campeão ou você prefere jogar todos os jogos, mesmo sabendo que o time irá perder o campeonato?”. Mais da metade (60\%) dos adolescentes optou por permanecer reserva e ser campeão, outros $40 \%$ optaram por jogar e perder o campeonato.

Analisando os dados e comparando-os com os resultados do estudo desenvolvido por FERRAZ (1997), notamos diferença significativa nas amostras. Enquanto na pesquisa de FERRAZ (1997), todos os adolescentes (100\%), na faixa etária de 16,5 anos, preferem jogar todos os jogos, mesmo sabendo que seu time perderá o campeonato, neste estudo, esse percentual atinge, apenas, $60 \%$ da população.
Podemos supor, com os resultados, que, para a maioria dos adolescentes, do presente estudo, competir e participar do jogo de futsal não parece ser tão importante quanto ser campeão. Talvez competir não seja um atrativo motivacional, para esses adolescentes, porque isso implicaria esforçar-se, mobilizar recursos internos e acreditar na capacidade de vencer dificuldades.

Importante salientar que adolescentes, institucionalizados, vivenciaram e, ainda, vivenciam, situaçôes de risco, como negligência, abandono, violência e abuso, tanto familiar como social. Também permanecem em constante vulnerabilidade, marcados por defasagens socioeconômicas e culturais e isso, de certa forma, favorece baixa auto-estima.

A competição, para muitos deles, torna-se difícil pelo próprio contexto social e pelas dificuldades econômicas em que vivem. Para eles o importante é ganhar o jogo, e, se for sem esforços, será melhor, ainda, porque esforço remete à luta para vencer obstáculos, e muitos não acreditam na sua capacidade.

Analisando as respostas da questão "Você prefere ganhar a partida de futsal trapaceando ou prefere perder a partida, mas jogar corretamente?”. A maioria $(90 \%)$ dos adolescentes prefere perder a partida, mas jogar honestamente. No entanto, isto ocorre por medo ou receio de serem expulsos e pela lealdade à regra e ao grupo, conforme o relato de $\mathrm{Y}$ (17 anos) "Prefiro jogar corretamente porque não adianta roubar no jogo, porque posso ser expulso, ser chamado de ladrão e sofrer gozaçóes do tipo: só ganha roubando."

Apenas 10\% optaram por ganhar desonestamente, conforme o relato de C (18 anos) "Prefiro ganhar com trapaças para ter chance de participar de outro jogo". Confirmamos uma característica da fase da heteronomia de Piaget (1994), ou seja, a regra é considerada lei e deve ser mantida por consentimento mútuo. A lealdade ao grupo exige que seja respeitada e sua mudança só poderá ocorrer por consenso geral. Nessa fase, o adolescente tem consciência do caráter arbitrário e necessário das regras, resultado da cooperação e aceitação mútua entre os competidores.

$\mathrm{Na}$ questão "Você prefere roubar no jogo para ganhar ou prefere perder o jogo, mas jogar corretamente? Por quê?”. Apenas 6,7\%, dos adolescentes, optaram por roubar no jogo para ganhar, pois este resultado seria melhor, independentemente das consequências.

A maior parte dos adolescentes $(93,3 \%)$ prefere perder o jogo, mas jogar corretamente, porque acreditam no reconhecimento dos seus esforços, conforme os relatos: B (18 anos) "Prefiro jogar corretamente porque fico com a consciência limpa e mostro 
meu caráter"; L (18 anos) "Prefiro perder, mas jogar de maneira correta, porque é melhor perder lutando do que ganhar roubando" e U (16 anos) "Prefiro perder, mas jogar correto porque roubando chega uma hora que não dá certo, na vida há muitas leis e as leis é pra serem respeitadas. No nosso caso não respeitamos a lei de fora e viemos para cá".

A análise das entrevistas e observaçōes, bem como a discussão dos dados, possibilitou a articulação das informaçōes, com as características das fases do desenvolvimento moral (PIAGET, 1994). Ressaltamos que o grupo apresentou características, somente da fase da heteronomia, não havendo nenhum adolescente com características da fase da autonomia.

Durante as observaçôes dos jogos, analisamos a disponibilidade dos recursos cognitivos e morais dos adolescentes, para a prática do futsal. Salientamos que, durante a partida de futsal, não houve a figura do juiz (autoridade). Cada jogador desempenhou o papel de árbitro e as faltas eram marcadas, ou não, por eles.

Através das entrevistas estruturadas, notamos o conhecimento das regras do futsal pelos adolescentes. Para eles, as regras são consideradas leis e devem ser mantidas e respeitadas por consentimento mútuo e pela lealdade ao grupo, como preconiza Piaget (1994) sobre a fase da heteronomia.

No entanto, na observação da prática do futsal, notamos que, quando sozinhos e na ausência da figura do juiz, que dentro do jogo de futsal representa a figura de autoridade, a situação mostra-se inversa aos dados coletados na entrevista. Tais nuanças serão expostas a seguir: a) os adolescentes possuem sutilezas técnicas e habilidades para a prática do futsal, principalmente, quando a intenção é favorecer uma jogada a favor do seu time; b) apesar da regra impor limite para jogar e normatizar as relaçōes e interações, entre eles, agem, intencionalmente, contra ela; c) aderem a um sistema de recompensa e motivação que é, simplesmente, ganhar o jogo; d) não enfrentam as situações de desobediência à regra, talvez, por não

\section{Conclusões e implicações}

Em nosso estudo, procuramos identificar a noção de regras, de adolescentes em conflito com a lei, entre 15 e 18 anos, no jogo de futsal. Nossa hipótese era a de que esses adolescentes poderiam apresentar noções de regras compatíveis com as características da fase da heteronomia, preconizada por PIAGET (1994), em seus estudos sobre moralidade. conseguirem reconhecer seus erros e faltas ou por quererem levar vantagem da situação, do jogo; e) desrespeitam as regras, não por pura incompreensão ou incompetência, mas, sim, como estratégia para levar vantagens na competição; f) quanto à honestidade, podemos considerá-los desonestos, porque burlam as regras com objetivo de ter vantagens para ganhar o jogo, pois, para eles, se houver honestidade ficará difícil conseguir a vitória; g) respeitam somente as regras que favorecem o seu time; $h$ ) são exigentes com o time adversário, nas cobranças de faltas, quando este desobedece à regra, e com parceiros, somente, nas cobranças de faltas que favoreçam o time ou na marcação do gol; i) geralmente, são individualistas nas jogadas, tentando marcar o gol ou fazer uma jogada que leve ao gol, sem a cooperação dos integrantes do time; j) a intenção do jogador é jogar bola, divertir-se, ganhar a partida e favorecer o seu time com vantagens que vão desde a não marcação das faltas e cobranças incorretas e k) os adolescentes, quando ganham trapaceando, não admitem que a vitória foi injusta e, ainda, fazem chacotas com o time perdedor.

Diante dessas constatações podemos supor que os adolescentes da pesquisa e inseridos em medida socioeducativa de internação, quando praticam o jogo de futsal, sem a figura de autoridade (juiz), que lhes impõem regras e os direcionam para a prática correta do esporte, não conseguem respeitar e nem se esforçam para obedecer às regras ditadas pelo esporte. Também não se respeitam, mutuamente, uma vez que a lei maior para eles, durante a partida de futsal, é levar vantagem da situação, através da desobediência das regras e ganhar o jogo de qualquer maneira.

A observação do jogo de futsal nos reporta a refletir a respeito das respostas, sobre os dilemas morais, enunciados na entrevista, pelos adolescentes. Percebemos diferenças entre a prática e consciência das regras, principalmente, quando abordamos questões sobre obediência, respeito mútuo, medo de puniçôes e repreensôes.

Diante do resultado da análise, confirmamos nossa hipótese, de que esses adolescentes, ainda, se encontram com características de uma moral heteronomica. Pois, tanto as informações coletadas pela entrevista estruturada, baseada no método clínico, como conclusôes feitas, a partir das observações realizadas durante as partidas do jogo de 
futsal, levaram-nos a descrição do comportamento desses adolescentes, configurando-lhes características próprias na situação pesquisada que são indicativos dessa fase.

Diante das observaçôes realizadas, durante a partida do jogo de futsal, que não contou com a figura do juiz para impor regras, notamos diferenças entre a prática e a consciência da regra. Apesar de apresentarem consciência da sua existência, não a respeitam com o intuito de obter benefício, no decorrer da partida, como, não cobrar a falta, enganar o adversário ou, simplesmente, ganhar a partida. Presuminos que somente respeitariam as regras do jogo, caso houvesse a figura de autoridade, porque iria lhes impor punições e privações. $\mathrm{O}$ contrário mostrou-se verdadeiro, por preferirem impor as facilidades que as vantagens que a situação confere-lhes.

Também supomos que essa característica de desobedecer às regras do jogo de futsal, e impor a lei que acreditam trazer gratificações e benefícios, também, permeie a atitude do adolescente para infringir a lei e, assim, cometer atos infracionais.

$\mathrm{O}$ adolescente conhece regras e normas, porém as desacatam, talvez, por acreditar que não será castigado e nem punido pelo ato infracional cometido, e isto, infelizmente, favorece a prática de outros atos infracionais até que seja descoberto, apreendido e punido.

Para Piaget (1994), o tipo de relação social mantida com o grupo familiar e social, na mais tenra idade, influencia o desenvolvimento moral. Acreditamos que pesquisas direcionadas a analisar o ambiente familiar e social possam articular projetos preventivos com o objetivo de diminuir a incidência de adolescentes na criminalidade e promover, portanto, seu desenvolvimento moral.

Neste estudo, nenhum adolescente foi identificado com características da fase da autonomia (PIAGET, 1994), caracterizada pelo princípio de igualdade, respeito mútuo e relações de cooperação. Para que adolescentes em medida socioeducativa alcancem essas características e, consequentemente, seu desenvolvimento moral, será imprescindível promover situações questionadoras para reverem atitudes e posturas.

Diante da discussão permanecem duas questôes importantes: o comportamento do adolescente, em situação de reeducação, seria diferente quando reintegrado na sociedade? Que garantia teríamos de que esses comportamentos heteronômicos apresentados, neste estudo, estariam restritos, apenas, aos afetos e desafetos no decorrer do jogo de futsal? Isto, certamente, seria um novo ciclo de pesquisas que se iniciaria diante dessas questôes.

Sabemos que as políticas públicas devem garantir investimentos em educação, não só para o desenvolvimento de habilidade e competência intelectual, mas também moral. Propostas e projetos direcionados ao desenvolvimento sociomoral, devem ser aplicados, indiscriminadamente, a crianças e adolescentes, de modo a favorecer o desenvolvimento da moralidade.

A implantação dessas propostas implicaria diminuição da participação de adolescentes, em situação de risco, na criminalidade, e, preventivamente, na diminuição da inserção, desta população, em medidas socioeducativas, principalmente a de caráter mais severa, como é a internação.

Acreditamos, portanto, que os resultados deste estudo possam tornar-se um parâmetro para educadores que atuam, junto a crianças e adolescentes, em medidas socioeducativas ou de proteção. Eles podem criar situaçóes propícias, tanto preventivas como interventivas, para propiciar o desenvolvimento sociomoral, minimizando, assim, sofrimentos e oportunizando a formação de cidadãos com maior senso ético e moral, capazes de optarem pelo caminho da solidariedade, da cooperação e da justiça.

\section{Abstract}

\section{Adolescent in conflict with the law and his notion of rules in the court soccer game}

Adolescents with a course of life based on the lack of ethical and moral values are more vulnerable to the practice of infractions, and in this case the statute of the child and adolescent assumes their insertion on socio educative measures. The objective of this research is to identify the moral development phase in adolescents who are in conflict with the law. Thirty male adolescents between fifteen and eighteen years old, who are inserted on the socio educative care Center, were studied. Data were collected through futsal game observation, without the presence of a referee and structured interview, according to the general lines of the Clinical Method of PIAGET (1994). The arrangement of the collected 
data confirmed our hypothesis - these adolescents are still with the characteristics of a heteronomical moral, confirmed by the differences between conscience and the practice of rules in a game situation. Although they know the rules, these are only respected in order to get some benefits, like not charging foul, deceive the opponent or simply win the match. It is presumed that the rules would only be respected in the presence of an authority (referee), because he would impose punishments and privations. However, it is believed that the results of this study may become a parameter to educators in order to create favorable situations which can be preventive and interventive to the socio moral development, minimizing suffering and seizing opportunities to the formation of citizens with higher ethical and moral standards, who are able to choose the way to the solidarity, cooperation and justice.

UnITERMS: Game of rules; Adolescent in conflict with the law; Moral; Court soccer.

\section{Referências}

BRASIL. Ministério da Saúde. Estatuto da criança e do adolescente: Lei no 8.069, de 13 de julho de 1990. 3. ed. Brasília: Editora do Ministério da Saúde, 2006.

BUNCHAFT, G.; KELLNER S.R.O.; HORA, L.H.M. (Colab.). Noções de amostragem. In: Estatística sem mistérios. Petrópolis: Vozes, 1998.

CHRISTINO, R.R. Estudos da moralidade: do comportamento real ao comportamento virtual. Disponível em <www. anped.org.br/reunioes/26/trabalhos/raquelrosachristinogitahy.p>. Acesso em: 23 set. 2006.

DELVAL, J. Introdução à pratica do método clínico: descobrindo o pensamento das crianças. Porto Alegre: Artmed, 2002. DIAS-AGUADO, M.J.; MEDRANO, C. Construção moral e educação: uma aproximação construtivista para trabalhar os conteúdos transversais. Tradução Orlando Fonseca. Bauru: EDUSC, 1999.

FERRAZ, O.L. O desenvolvimento da noção de regras do jogo de futebol. Revista Paulista de Educação Fisica, São Paulo, v.11, n.1, p.27-39, 1997.

FONTANA, C.E. A socialização de crianças através de jogos. Mogi das Cruzes, 1997. Disponível em: <http://www. brazcubas.br/professores/sdamy/mfcnm02.html>. Acesso em: 23 set 2006.

KOBAYASHI, M.C.M.; ZANE, V.C. Desenvolvimento sociomoral de adolescentes inseridos em medida de internação: um estudo inicial. 2007. 119f. Monografia (Curso de Especialização em Psicopedagogia) - Universidade do Sagrado Coração, Bauru, 2007.

KUWAHARA, M.C.M. Jogos no processo de aprendizagem. out. 2004. Disponível em:<http://www.psicopedagogia. com.br/artigos/artigo.asp?entrID=598>. Acesso em: set. 2006.

LUDKE, M.; ANDRE, M.E.D. A pesquisa em educação: abordagens qualitativas. São Paulo: EPU, 1986.

PIAGET, J. A formação do símbolo na criança: imitação, jogo e sonho, imagem e representação. Tradução de Álvaro Cabral e Christiano Monteiro Oiticica. 2. ed. Rio de Janeiro: Zahar, 1975.

O juízo moral na criança. Tradução Elzon Lenardon. 2. ed. São Paulo: Summus, 1994. . A representação do mundo na criança. Rio de Janeiro: Record, s.d.

\begin{tabular}{r|r} 
ENDEREÇo & \\
Maria do Carmo Monteiro Kobayashi & \\
Faculdade de Ciências & Recebido para publicação: 14/03/2008 \\
Departamento de Educação & 1a. Revisão: 16/o9/2009 \\
Universidade Estadual Paulista & 2a. Revisão: 19/10/2009 \\
Av. Eng. Luiz Edmundo Carrijo Coube, 14-01 & Aceito: 22/10/2009 \\
17033-360 - Bauru - SP - BRASIL & \\
e-mail: kobayashi@fc.unesp.br & \\
\hline
\end{tabular}

204 • Rev. bras. Educ. Fís. Esporte, São Paulo, v.24, n.2, p.195-204, abr./jun. 2010 